\title{
PULMONARY ATRESIA DEVELOPING AFTER A SHUNT OPERATION FOR FALLOT'S TETRALOGY
}

\author{
BY \\ J. FABRICIUS, P. FRITZ HANSEN, AND O. LINDENEG \\ From the Medical Department B (Physician-in-chief, Prof. E. Warburg), and the Cardiological Laboratory \\ (Head: Dr. A. J. Hansen) Rigshospitalet, Copenhagen, Denmark \\ Received March 3, 1961
}

Experience has proved that certain forms of congenital malformations of the heart are transformed into other types after birth. Thus, Gasul et al. (1957) demonstrated that some infants with ventricular septal defects may develop infundibular pulmonary stenosis. In this paper we shall show that pulmonary atresia may develop post-natally in patients with the tetralogy of Fallot. On the basis of clinical and hæmodynamic findings in these patients, the hypothesis is put forward that the infundibular pulmonary stenosis may be progressive with the years and that pulmonary atresia may arise when the collateral circulation of the lungs is adequate for survival.

Of 120 patients with Fallot's tetralogy who were followed over periods from five to ten years after Blalock-Taussig operation, 3 developed pulmonary atresia. At cardiac catheterization ten years earlier in these three patients, a catheter could be introduced into the pulmonary trunk. Later, at open-heart surgery, complete fusion of the pulmonary valves was found in one, and on angiocardiography a closure was found to be localized at the infundibulum of the right ventricle in the other two.

None of the patients have had symptoms of endocarditis, and their course was uniform, with improvement for several years after the anastomotic operation, followed by regression. The systolic murmur over the pulmonary artery disappeared in two and diminished considerably in the third.

\section{Case Reports}

Case I (No. 224). An 18-year-old girl was first seen in this hospital in 1947 at the age of 5. She showed constant cyanosis and poor functional capacity with squatting. There was a harsh systolic murmur in the third left intercostal space, the second pulmonic sound was louder than the second aortic sound. In 1949 she was more cyanosed, her hæmoglobin was 150 per cent, and the arterial oxygen saturation was found to be 74 per cent. The electrocardiogram showed right axis deviation of +150 degrees and a prominent $P$ wave in lead II. Rœntgenogram showed normal configuration of the heart (cardiothoracic ratio 0.55 ) and the central vascular markings of the lungs were diminished. At catheterization the pulmonary artery was entered and a pulmonary valvular stenosis was found, with a systolic gradient of $100 \mathrm{~mm} . \mathrm{Hg}$ and equalized pressures in the ventricles. The diagnosis was tetralogy of Fallot.

The same year, an anastomosis between the subclavian artery and the left pulmonary artery was carried out: the latter was fairly large and thin-walled with low pressure. The first three years after operation her condition was much improved, and she was able to take long walks and to lead a normal school life. Thereafter she became worse over a period of two years, and at last she had to stay in bed most of the time on account of dyspnœa.

On admission in 1955, the patient was deeply cyanotic. A faint systolic murmur was heard over the præcordium and a continuous murmur under the left clavicle. Hæmoglobin was 160 per cent and the arterial oxygen saturation was 77 per cent (see Table I). The cardiogram was unchanged, and the chest rontgenogram showed an improved supply of blood to the lungs. At catheterization it was not possible to enter the pulmonary artery, and the catheter entered the aorta. On angiocardiography with injection of 70 per cent diodone into the right atrium, the entire volume of contrast medium was seen to pass from the right ventricle into the aorta. The conus of the right ventricle was filled through an infundibular stenosis, and during 
systole the pulmonary valves formed a dome, but no outlet to the pulmonary trunk was seen. Later on, the pulmonary artery was filled through the anastomosis.

At a second operation, the right pulmonary artery was found to be so narrow that a Blalock-Taussig operation was not practicable. The pleura were then treated by Barrett's method. The collateral circulation to the lungs was strongly developed and the pulmonary valves seemed to be atretic. The operation produced only transient improvement. In 1960 severe cyanosis was observed, the murmurs had disappeared and the hæmoglobin was 175 per cent. The cardiogram and rœntgenogram were unchanged.

TABLE I

Findings of our Patients before and after Shunt-operation and after Pulmonary Atresia had DEVELOPED

\begin{tabular}{|c|c|c|c|c|c|c|c|c|c|c|c|c|}
\hline \multirow{2}{*}{ Case } & \multicolumn{3}{|c|}{$\begin{array}{l}\text { Hæmoglobin } \\
\text { percentage }\end{array}$} & \multicolumn{3}{|c|}{$\begin{array}{l}\text { Hæmatocrit } \\
\text { percentage }\end{array}$} & \multicolumn{3}{|c|}{$\begin{array}{c}\text { Arterial oxygen } \\
\text { saturation (per cent) }\end{array}$} & \multicolumn{3}{|c|}{$\begin{array}{c}\text { Cardiothoracic } \\
\text { ratio }\end{array}$} \\
\hline & $\begin{array}{l}\text { Pre- } \\
\text { opera- } \\
\text { tive }\end{array}$ & $\begin{array}{l}\text { Before } \\
\text { atresia* }\end{array}$ & $\begin{array}{l}\text { After } \\
\text { atresia }\end{array}$ & $\begin{array}{l}\text { Pre- } \\
\text { opera- } \\
\text { tive }\end{array}$ & $\begin{array}{l}\text { Before } \\
\text { atresia* }\end{array}$ & $\begin{array}{l}\text { After } \\
\text { atresia }\end{array}$ & $\begin{array}{l}\text { Pre- } \\
\text { opera- } \\
\text { tive }\end{array}$ & $\begin{array}{l}\text { Before } \\
\text { atresia* }\end{array}$ & $\begin{array}{l}\text { After } \\
\text { atresia }\end{array}$ & $\begin{array}{l}\text { Pre- } \\
\text { opera- } \\
\text { tive }\end{array}$ & $\begin{array}{l}\text { Before } \\
\text { atresia* }\end{array}$ & $\begin{array}{l}\text { After } \\
\text { atresia }\end{array}$ \\
\hline I & 150 & - & 160 & - & - & - & 74 & - & 77 & 0.55 & 0.60 & 0.52 \\
\hline II & 156 & 123 & 150 & 79 & 64 & 75 & 58 & - & 65 & 0.44 & 0.48 & 0.44 \\
\hline III & 188 & 100 & 156 & 75 & 46 & 78 & 70 & 84 & 71 & 0.50 & 0.57 & 0.52 \\
\hline
\end{tabular}

* After shunt-operation.

The same year, the patient was operated on with an extracorporeal circulation and hypothermia. The infundibulum was found to be extremely narrow and the pulmonary valves were completely fused. The Blalock-Taussig anastomosis had closed. The pulmonary valves were divided, the infundibular stenosis was resected, and the ventricular septal defect was closed. The patient died 24 hours after operation. Necropsy was not performed.

Case II (No. 389). A 24-year-old woman, on her first admission to this hospital in 1950 she was 14 years old. When a year old, she was noticed to be breathless on exertion. Later on she became cyanotic and squatting was observed: she could not take part in play and could only run a few steps. On admission severe cyanosis was observed, her fingers showed clubbing, there was a systolic thrill in the præcordium. and a grade III systolic murmur was heard in the third left intercostal space. The hæmoglobin was 156 per cent, hæmatocrit 79 per cent, and the arterial oxygen saturation 58 per cent. The cardiogram showed a QRS axis of 120 degrees and right ventricular hypertrophy. The rœntgenogram showed a normal pulmonary artery and small central lung vessels with normal peripheral vascular markings of the lungs. At catheterization an infundibular pulmonary stenosis was found with a pressure gradient of $80 \mathrm{~mm}$. $\mathrm{Hg}$ and equalized pressures in the ventricles. Furthermore, the catheter passed through a defect in the atrial septum, though there was no left-to-right shunt. The diagnosis was Fallot's tetralogy with an unsealed foramen ovale. An anastomosis was completed between the left axillary artery and the pulmonary artery which was found to be of normal size. The anastomosis did not seem to function satisfactorily during the operation.

Six months later, the patient was again admitted. She was much improved, was able to walk about out-doors, and did not squat so often. A loud, harsh, systolic murmur was heard in the second left intercostal space, but no continuous murmur was audible. The patient was admitted again in 1955, now 19 years old. She was only able to move about indoors and was deeply cyanotic. There was a grade II systolic murmur, but no continuous murmur. The hæmoglobin was 123 per cent and the hæmatocrit 64 per cent. A right-sided anastomosis was planned, but was not practicable, the pulmonary artery only being 5 to $6 \mathrm{~mm}$. in diameter. Consequently, the pleura was treated by Barrett's method.

After transient improvement her condition gradually deteriorated and in 1960 no murmur was heard over the heart. The hæmoglobin had risen to 150 per cent without much change in the other findings. At catheterization the pulmonary trunk could not be entered: the pressures in the ventricles were identical, and both aorta and left atrium were entered. Angiocardiography was performed with injection of $60 \mathrm{ml} .76$ per cent urografin in the right atrium. The contrast medium was seen to pass from the right ventricle into an enlarged aorta without filling the conus of the right ventricle. There was no connection between the right ventricle and the pulmonary artery, and the Blalock-Taussig anastomosis did not function. Part of the contrast medium passed through the atrial septal defect into the left ventricle. 
Case III (No. 254). A 23-year-old man had first been admitted to this hospital in 1949, when 11 years old. At the age of 6 months, attacks of cyanosis had appeared, and later he developed dyspnœa on exertion and squatting. On admission, he could walk 100 metres slowly, was deeply cyanotic, and had Hippocratic fingers. A grade IV systolic murmur was heard in the second left intercostal space. The hæmoglobin was 188 per cent, the hæmatocrit 75 per cent, and the arterial oxygen saturation 70 per cent. The cardiogram showed a QRS axis of 135 degrees and right ventricular hypertrophy. Rœntgenogram showed the heart to be of normal size and shape, with a cardiothoracic ratio of 0.50 . The pulmonary artery was dilated, and the vascular markings of the lungs were normal. At catheterization the pulmonary trunk was entered and a pulmonary stenosis was revealed with a gradient of $100 \mathrm{~mm}$. $\mathrm{Hg}$ and equalized pressures in the ventricles. It was not possible to determine whether the pulmonary stenosis was valvular or infundibular. The diagnosis was Fallot's tetralogy. An anastomosis was completed between the left subclavian artery and the pulmonary artery. Examination six months later showed the condition to be good. The patient could now walk 2 kilometres, run 100 metres and bicycle, and no longer squatted. A loud systolic murmur was heard in the third left intercostal space and a continuous murmur below the left clavicle.

In 1954, the condition had deteriorated and there was moderate cyanosis. The systolic murmur had diminished to grade II, the continuous murmur was unchanged. Hæmoglobin was 136 per cent (see Table I). On angiocardiography with injection of contrast medium in the subclavian vein, the pulmonary trunk was filled through a narrow infundibulum, but the greater part of the contrast medium passed from the right ventricle into the aorta. The anastomosis was not visible (Fig. 1).

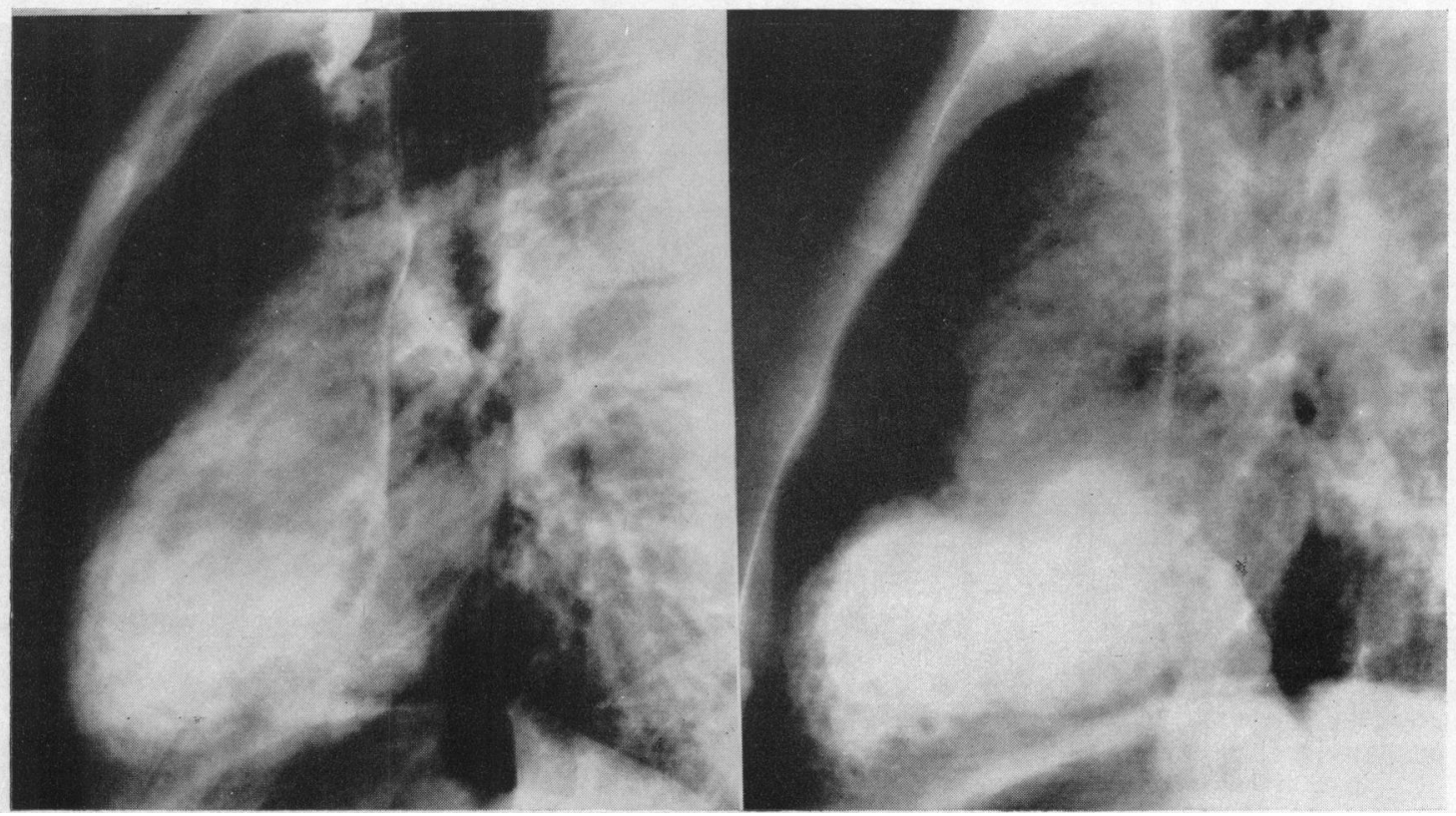

Fig. 1.-Patient III. Angiocardiograms, lateral view. Left (1954). Infundibulum of the right ventricle and the pulmonary trunk are outlined. Right (1960). No filling of the conus or of the pulmonary artery can be seen.

The patient was re-admitted six months later because his condition had become even worse. The systolic murmur was unchanged, and the continuous murmur was still present. The hæmoglobin had risen to 150 per cent, and the arterial oxygen saturation was 82 per cent. A second angiocardiogram was performed with injection into the right atrium. Most of the contrast medium passed from the right ventricle out into the aorta, the pulmonary artery filled, but it was not possible to see whether it filled from the right ventricle or through the visible anastomosis. The infundibulum was extremely narrow and pronounced collateral vessels were seen in the left lung field.

In 1960, the condition was much worse, and the patient was deeply cyanotic. The systolic murmur was only of grade I intensity and a faint continuous murmur was heard. The hæmoglobin was 156 per cent, and the arterial oxygen saturation was down to 71 per cent. Rœntgenogram revealed a slightly enlarged heart with prominence of the pulmonary artery. The catheter failed to enter the pulmonary trunk while 
it easily entered the aorta. Systemic flow: $5700 \mathrm{ml} . / \mathrm{min}$. Pulmonary flow: $3810 \mathrm{ml} . / \mathrm{min}$. At bronchospirometry the flow in the right lung was determined by Fick's method as $1650 \mathrm{ml} . / \mathrm{min}$. and in the left lung as $2160 \mathrm{ml} . / \mathrm{min}$. Angiocardiography with injection of urografin in the right atrium showed that the contrast medium passed directly from the right ventricle out into the aorta and that the conus of the right ventricle did not fill. No contrast appeared in the pulmonary artery and the Blalock-Taussig anastomosis was not visible (Fig. 1).

\section{Discussion}

In each of our three patients progressive infundibular pulmonary stenosis was demonstrated, accompanied by development of pulmonary atresia. In two, the atresia was localized at the infundibulum of the right ventricle, but in the third complete fusion of the pulmonary valves was found. In our opinion, the only explanation of the valvular atresia must be that during the narrowing of the infundibulum the pulmonary valves had been fused together by formation of fibrin which was later on transformed into fibrous tissue.

The same uniform course of disease with improvement after a shunt-operation, followed by gradual deterioration without any relation to thrombosis of the established anastomosis has been described by Campbell (1958). In his series comprising 165 shunt-operations for the tetralogy of Fallot, a similar course was encountered in 12 cases: in two of these an almost atretic infundibulum was found at subsequent operation and at necropsy. In patients with Fallot's tetralogy, Wood (1958) and Braudo and Zion (1959) have described periodic closure of the infundibulum, and this might be a transitional stage on the way to permanent obstruction. In our patients the systolic murmur over the pulmonary artery disappeared or diminished. Similar observations have been made by Vogelpoel and Schrire (1960), who maintain that the intensity of the murmur is dependent on the pulmonary blood flow.

A large pulmonary collateral circulation must be essential for surviving a closure of the infundibulum and for allowing sufficient time for development of pulmonary valvular atresia. In our three patients the peripheral vascular markings of the lungs were little, if at all, reduced at the first examination and somewhat increased after the shunt-operation. In Case III the established anastomosis was closed before the atresia developed, but the collateral circulation was probably increased through pleural adhesions resulting from the operation.

Consequently, pulmonary atresia may develop in patients with Fallot's tetralogy who have a large pulmonary collateral circulation. Diminution of the systolic murmur over the pulmonary artery in connection with deterioration of the clinical condition suggests that pulmonary atresia has developed. Pulmonary atresia should be born in mind, particularly as a complication in patients who have had a shunt operation, but also in non-operated subjects, where such a development is possible, since the collateral circulation may be sufficient, as is the case in pseudo-truncus.

Whether the pathogenesis outlined above also may explain pulmonary atresia in patients with intact ventricular septum depends on the presence of an infundibular pulmonary stenosis in these cases. It is, however, difficult to decide on this problem, the right ventricle being heavily hypertrophied with an extremely narrow lumen (Allanby et al., 1950, and Edwards, 1960).

\section{SUMMARY}

Three patients with Fallot's tetralogy are described, in whom pulmonary atresia developed from 5 to 10 years after an anastomotic operation. Before operation, the pulmonary trunk had been catheterized in all three. Later, during open-heart surgery, a valvular atresia was found in the first and an infundibular obstruction was demonstrated at angiocardiography in the other two. The murmur disappeared in two of the patients and diminished in the third. In our opinion the infundibular stenosis will eventually be able to close the outlet of the right ventricle and thereby give rise to atresia of the pulmonary valves. Survival after such a closure is only possible when there is an adequate collateral pulmonary circulation. 
Allanby, K. D., Brinton, W. D., Campbell, M., and Gardner, F. (1950). Guy's Hosp. Rep., 99, 110. Braudo, J. L., and Zion, M. M. (1959). Brit. med. J., 1, 1323.

Campbell, M. (1958). Brit. med. J., 2, 1175.

Edwards, J. E. (1960). In S. E. Gould's Pathology of the Heart. 2nd ed., Charles C. Thomas, Springfield. Gasul, B. M., Dillon, R. F., and Vrla, V. (1957). Amer. J. Dis. Child., 94, 424.

Vogelpoel, L., and Schrire, V. (1960). Circulation, 22, 73.

Wood, P. (1958). Brit. Heart J., 20, 282. 